\title{
Entre la benevolencia y la sospecha: los actores políticos de Córdoba ante el golpe de 1943 y el fin de la experiencia sabattinista ${ }^{1}$
}

\section{Between benevolence and suspicion: political actors in Córdoba facing the putsch of 1943 and the ending of the experience led by Sabattini}

\author{
CésarTcach \\ Consejo Nacional de Investigaciones Científicas y Técnicas \\ Centro de Estudios Avanzados \\ Universidad Nacional de Córdoba \\ (Argentina) \\ cesartcach@gmail.com
}

\begin{abstract}
Resumen
En contraste con el plano nacional, el golpe de 1943 en Córdoba no puso punto final a un gobierno marcado por el fraude electoral y las restricciones a las libertades públicas, sino a un gobierno democráticamente electo que estaba en manos del Partido Radical: entre 1936-1943, Córdoba vivió un período caracterizado por la vigencia plena de los mecanismos republicanos y la competencia política interpartidaria. Esta peculiaridad descansó en una dinámica bipartidaria -radicales y conservadores- pero también en una importante influencia de los partidos de izquierda y la Iglesia Católica en el juego político provincial.
\end{abstract}

1. Este texto es resultado del PICT 2013-0843/BID, "Las formas de mediación y producción del sufragio. El problema del partido mirado en clave comparada desde las experiencias provinciales (Santa Fe, Córdoba, Corrientes, Tucumán, 1890-1943". Se vincula, asimismo, con mi proyecto de investigación para Consejo Nacional de Investigaciones Científicas y Técnicas (CONICET): "La experiencia sabattinista: partidos políticos, gobierno y oposición en Córdoba (1936-1943). 
Este artículo ofrece una reconstrucción historiográfica del comportamiento de los principales actores políticos ante la Revolución de junio, desde una perspectiva de análisis que asocia su rol en la política provincial con su horizonte de expectativas derivado del plano nacional. Desde este ángulo de preocupaciones, se presta especial atención a las tensiones internas provocadas en la Unión Cívica Radical (UCR) y el Partido Demócrata (PD), así como a las distintas miradas sostenidas desde los partidos de izquierda y la Iglesia Católica. Asimismo, se pone en diálogo lo ocurrido en Córdoba con las distintas interpretaciones del fenómeno en el plano nacional.

Palabras Clave: Actores políticos - Democracia - Golpe militar

\begin{abstract}
In contrast to the national level, the 1943 putsch in Córdoba did not put an end to a government constrained by electoral fraud and restrictions on civil liberties, but to a democratically elected government that was in the hands of the "Partido Radical": between 1936- 1943, Córdoba experienced a period characterized by the full force of Republican policy mechanisms and inter party competition. This singularity rested in a two party system ("radicales" and conservatives) and in the important influence of the left parties and the Catholic Church in the provincial political game.

This article provides a historiographical reconstruction of the behavior of the main political actors before the Revolution of June, from an analytical perspective that associates their role in provincial politics with its horizon of expectations derived from the national level. From this angle of concerns, we focus on the internal tensions caused in the "Unión Cívica Radical" (UCR) and the "Partido Demócrata" (PD) as well as on the different views held from the left parties and the Catholic Church. It also puts in dialogue what happened in Cordoba with the different interpretations of the phenomenon at national level.
\end{abstract}

Key Words: Political actors - Democracy - Putsch

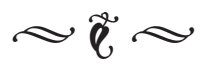

\section{Introducción}

Distintos autores han trazado puentes que asocian con diversos matices a sectores del Partido Radical con el golpe del 4 de junio de 1943. Ricardo Sidicaro recordó que el Movimiento Radical Revisionista de la provincia de Buenos Aires (crítico de la dirección oficial del partido) en un comunicado -que contó entre otras con las firmas de los jóvenes Ricardo Balbín y Oscar Alende- respaldó el levantamiento militar para terminar "con un régimen de bochorno". ${ }^{2}$ Robert Potash, por su parte, destacó que en la formación de la logia original que dio lugar

2. SIDICARO, Ricardo, La política mirada desde arriba, Sudamericana, Buenos Aires, 1993, p. 178. 
al nacimiento del Grupo de Oficiales Unidos (GOU), de los siete oficiales sólo dos no habían participado en el golpe de 1930, los hermanos Miguel Angel y Juan Carlos Montes, quienes tenían antiguos vínculos con la Unión Cívica Radical (UCR) y Amadeo Sabattini. Se podría añadir que el mismo 4 de junio, el teniente coronel Juan Carlos Montes aseguró a la revista Noticias Gráficas que el movimiento triunfante, "de absoluta esencia democrática" rompería las relaciones de Argentina con Alemania, Italia y Japón. ${ }^{3}$ Pero el perfil de estos oficiales, era minoritario en relación con los admiradores de los países del Eje en la guerra mundial, y en especial, de la dictadura de Franco en España. ${ }^{4}$ Precisamente, en este aspecto hizo hincapié Darío Macor, para quien la fuerte presencia del nacionalismo integrista durante la primera mitad del gobierno militar calificó el impacto de la impugnación a la tradición liberal. ${ }^{5}$

En un texto reciente, Fernando Devoto muestra como la incertidumbre que rodeó a la Revolución durante los primeros meses, potenciada por algunas medidas contradictorias y ciertas dosis de ambigüedad, habilitó la

3. Córdoba, Córdoba, 04/06/1943.

4. POTASH, Robert, El Ejército y la Politica en Argentina, T. I, Hyspamerica, Buenos Aires, 1985, pp. 266-268.

5. Al respecto, añadía: "Si bien ese nacionalismo tradicionalista, hispanófilo y católico, que colonizó sectores claves del poder hasta por lo menos fines de 1944, fracasa en definir el horizonte político desde sus registros, no puede ignorarse la fuerte impronta que dejó su intervención". Véase, MACOR, Darío e IGLESIAS, Eduardo, El peronismo antes del peronismo, Universidad Nacional del Litoral, Santa Fe, 1997, p. 22. Para una interpretación de los hechos de junio como corolario de la cruzada antiliberal de la Iglesia Católica (militarización de la política y clericalización del Ejército), véase ZANATTA, Loris, Del Estado Liberal a la Nación Católica, Universidad Nacional de Quilmes, Buenos Aires, 1996. convivencia involuntaria de expectativas contrapuestas sobre su orientación políticoideológica. ${ }^{6}$ Corroborando lo presumido por Devoto, ilustran didácticamente esta situación dos imágenes contrapuestas: mientras la Alemania hitleriana, la Italia fascista y la España franquista fueron los primeros países importantes de la época en reconocer al nuevo gobierno, el presidente- general Ramírez- otorgaba entrevistas a los dirigentes estudiantiles antifascistas de la Federación Universitaria Argentina (FUA) y les solicitaba su colaboración. ${ }^{7}$

A la luz de estas circunstancias, el escenario político cordobés presentaba rasgos singulares. Córdoba era gobernada desde 1936 por el radicalismo sabattinista (yrigoyenista), no se practicaba el fraude electoral, no había presos políticos ni gremiales, y los partidos de izquierda gozaban también de un clima pleno de libertades públicas. Enfrentado a un Partido Demócrata (PD) sumido en una irresuelta crisis política, era sede también de una poderosa guarnición militar (la División Cuarta de Ejército) y una influyente Iglesia Católica. Se trataba de un gobierno cuyas prácticas políticas y orientación ideológica distaban de parecerse a las del gobierno nacional. Empero, el golpe del 4 de junio implicó también el punto final para las autoridades provinciales. Al día siguiente, el gobernador radical Santiago del Castillo y su vice, Arturo Illia (electos en 1940), presentaron sus renuncias. El gobernador envió

6. DEVOTO, Fernando, "Para una reflexión del golpe del 4 de junio de 1943”, en Estudios Sociales, Santa Fe, 2014, No 46, p. 177. No obstante, recuerda también que ya para el día 6 de septiembre, el gobierno nacional decretó asueto administrativo en la administración pública en homenaje al golpe militar del general Uriburu. Ídem, p. 179 .

7. La Voz del Interior, Córdoba, 11/06/1943 y 12/06/1943. 
dos telegramas al "General de Brigada a cargo del Gobierno de la Nación”, Arturo Rawson. En el primero reconocía al nuevo gobierno, le comunicaba que se había declarado la ley marcial en todo el territorio provincial y que en conocimiento de los fines expuestos por la proclama militar, "expresa su adhesión a los mismos por compartirlos". En el segundo, (respuesta a otro de Rawson) informaba que reinaba el orden y la tranquilidad en Córdoba. ${ }^{8}$ Unas semanas más tarde, tras delegar provisoriamente su mando en el comandante de la IV División de Ejército Gral. Justo Salazar Collado, asumió como interventor federal en la provincia, el general de infantería (retirado) Alfredo Córdoba, quien era oriundo de Mendoza.

A lo largo del texto, se trata de aportar evidencia empírica en torno al tipo de expectativas y demandas de los actores frente al golpe de Estado. Se sostiene que en los partidos políticos primó un diagnóstico expectante y plagado de ambigüedades, que osciló entre el apoyo crítico y el rechazo al golpe. En la Iglesia Católica, en cambio, se observó una respuesta más contundente cifrada en la búsqueda de revertir dos rasgos claves de los gobiernos de Amadeo Sabattini (1936-40) y Santiago del Castillo (1940-43): el peso del laicismo en la educación y la tolerancia hacia los sindicatos de izquierda y el Partido Comunista (PC). ${ }^{9}$

8. Ídem, 06/06/1943.

9. Cabe mencionar como un texto previo interesado en esta problemática, la ponencia de ACHAVAL BECU, Inés y GONZALEZ ACHAVAL, María, "Repercusiones del golpe de 1943 en Córdoba. Actores y culturas políticas", ponencia presentada en VI Jornadas de Historia de Córdoba, Junta Provincial de Historia de Córdoba, 2006. Fue publicada en JUNTA PROVINCIAL DE HISTORIA DE CÓRDOBA, Córdoba entre campanas y chimeneas, Junta Provincial de Historia de Córdoba, 2007. Véase también: TCACH,

\section{Entre la emoción y la incertidumbre: la despedida radical}

En el atardecer del 19 de junio de 1943, una multitud rodeó la Casa de Gobierno de la ciudad de Córdoba. Amadeo Sabattini, haciéndose espacio entre la gente que lo vivaba estruendosamente, ingresó al edificio y abrazó, "sin palabras", a Santiago del Castillo, el gobernador que él había ungido como su sucesor al terminar su mandato en 1940 y que ahora venía a despedir. Mientras tanto, en la calle, se vivaba a los líderes radicales, a la democracia y a la patria. Cuando Santiago del Castillo salió de la Casa de Gobierno -situada en la céntrica calle 27 de abril- una multitud lo siguió en manifestación hasta su domicilio. $\mathrm{Al}$ llegar, lo estaba esperando su madre y el propio "Don Amadeo", quien se había anticipado. Ante la insistencia popular, hablo desde el balcón: "Córdoba ha sido la precursora de la Revolución del 4 de junio, porque aquí, en nuestra provincia, se han hecho efectivas, desde el gobierno radical, todas las libertades, porque se hizo una religión del respeto a la constitución y a las leyes; porque se practicó la honestidad admnistrativa... y se hizo realidad la ilusión de la justicia y el trabajo que iba tras el propósito de lograr una Córdoba industrial”. ${ }^{10}$ De este modo, y en su mirada, su caída no era corolario sino prefacio de una nueva época. E1 papel precursor atribuido a Córdoba -al hacer efectiva en los hechos la vigencia del régimen democrático- la ubicaba como una suerte de rostro anticipado del país. Empero, admitía en una suerte de confesión pública: "Razones

César, Sabattinismo y Peronismo, Sudamericana, Buenos Aires, 1991, pp. 49-52.

10. La Voz del Interior, Córdoba, Ídem, 20/06/1943. 
ajenas a nuestra voluntad nos obligan a hacer un alto en el camino, pero no en la lucha por nuestros ideales... Vuelvo al pueblo, pobre, como entré al gobierno". En la misma sintonía Arturo Illia expresó que la experiencia radical cordobesa era una forma de avanzar hacia la República y hacer "patriotismo práctico". ${ }^{11}$

Luego, Amadeo Sabattini, también asomado al balcón de la casa, tomó la palabra para advertir: "Realizamos el enorme sacrificio de deponer la autonomía de la provincia, en bien del país, que crujía por la negación de las libertades... No aventuremos ahora opiniones. Tengamos cuidado. Si las armas llegaron para regenerar, bien; pero sí ellos no lo hacen, aquí estamos, para hacer cumplir los postulados de la Unión Cívica Radical". ${ }^{12}$ Como puede apreciarse, la postura radical tenía un sesgo posibilista que suponía una suerte de apoyo condicional a las nuevas autoridades nacionales. En ese marco, se inscribió el debate que tuvo lugar en la sesión secreta que realizó el comité provincial tres días después. Tras ella, Santiago del Castillo -quien simultáneamente había tenido conversaciones con el presidente, general Ramírez y el ministro del Interior, coronel Gilbert- aceptó la presidencia de la Comisión Nacional de Coordinación de Transportes. ${ }^{13}$ Cuando Gilbert lo puso en posesión de su cargo, los discursos parecían augurar una nueva luna de miel entre Ejército y radicalismo. Mientras el ministro se esmeró en subrayar que el movimiento

11. Córdoba, Córdoba, 20/6/1943.

12. La Voz del Interior, Córdoba, 20/6/1943. También hicieron uso de la palabra, el vicegobernador Arturo Illia, y el presidente del comité provincial, Mauricio Yadarola. La casa de Santiago del Castillo estaba en la calle Olmos, dentro del área céntrica.

13. Ídem, 23, 25, y 26/06/1943. del 4 de junio no se hizo contra los partidos políticos ni contra los hombres políticos, el ex gobernador de Córdoba se refirió al "Ejército de la Patria" como "el depositario auténtico de las instituciones democráticas libres de la República”. ${ }^{14}$

\section{Crítica partidaria y disidencias internas en la UCR}

Al disolverse la legislatura provincial -por disposición del comandante de la IV División de Ejército, general Salazar Collado- el Dr. Arturo Illia, en su condición de vicegobernador y presidente del Senado, hizo constar "que al abandonar una función pública para cuyo desempeño fuera elegido por la decisión soberana del pueblo en comicios donde la libertad electoral fue plenamente garantizada y asegurado el libre ejercicio de los derechos individuales, la administración de esta Honorable Cámara se encuentra al día con un saldo disponible de $3680.34 \mathrm{~m} / \mathrm{n}$. ${ }^{15}$ Quedaba claro, pues, que la decisión soberana del pueblo no estaba siendo respetada.

El comité provincial de la UCR dijo en voz alta y de modo explícito aquello que Illia apenas insinuaba. Presidido por Mauricio Yadarola, sus integrantes consensuaron un documento, en el que si bien expresaban su apoyo al levantamiento militar recordaban a los jefes militares que en Córdoba no hubo fraude electoral ni corrupción, sino un gobierno honrado y progresista que constituía

14. Córdoba, Córdoba, 29/06/1943.

15. La Voz del Interior, Córdoba, 21/6/1943; Los

Principios, Córdoba, 21/6/1943. 
"un ejemplo de democracia, de legalidad, de orden y de decencia”. Y añadía:

Que frente a esta realidad intergiversable [sic], la intervención decretada implica una evidente contradicción entre los principios proclamados y el acto por el cual se allana un gobierno digno del mayor respeto. Contradicción que no se salva con el argumento de la incompatibilidad entre un gobierno central revolucionario y uno local surgido de la Constitución. En primer lugar, porque las provincias son entidades autónomas, se dan sus propias instituciones y se rige por ellas sin intervención del gobierno federal; y segundo, porque el propio gobierno nacional ha declarado que ya no es un gobierno de facto sino de la Constitución. ${ }^{16}$

Como puede apreciarse, el comité provincial argumentaba que el gobierno nacional se contradecía a sí mismo, y era inconsecuente tanto con su vocación democrática, como republicana y federal. En el bimestre siguiente, las dudas se acrecentaron. En agosto de 1943, un numeroso grupo de jóvenes radicales de la ciudad de Córdoba -entre los que se contaban Félix Martín y Carlos Arguello Lencinas- visitaron a Amadeo Sabattini en Villa María para expresarle el desconcierto por su criterio favorable a la permanencia de radicales en el gobierno del interventor federal, general Alfredo Córdoba. Sabattini mantuvo su postura favorable a la colaboración, pero distó de convencer a sus visitantes. Al regresar a la capital cordobesa decidieron renunciar masivamente: alrededor de 60 funcionarios radicales dimitieron de sus cargos. En rigor, esta actitud colectiva -que contaba con el aval del presidente del comité central cordobés,

16. La Voz del Interior, Córdoba, 21/06/1943. E1 destacado es mío.
Mauricio Yadarola- fue la semilla de la escisión en el interior del sabattinismo cordobés. ${ }^{17}$

En el orden nacional, la crisis ministerial de octubre de 1943 -que elevó al general Luis Perlinger al ministerio del Interior- potenció a los sectores nacionalistas y tradicionalistas católicos: Jordán Bruno Genta nombrado interventor en la Universidad Nacional del Litoral y Lisardo Novillo Saravia en la Universidad Nacional de Córdoba. Asimismo, Mario Amadeo fue nombrado ministro de Relaciones Exteriores. ${ }^{18}$ En este contexto, Mauricio Yadarola pagaría con su cargo en la universidad -era desde hacía 16 años profesor de la cátedra de Derecho Comercialel precio de sus disidencias. Ante la cesantía de numerosos profesores universitarios como represalia por haber pedido "la normalización institucional, reiteradamente prometida en proclamas, juramentos y declaraciones públicas por los hombres que han asumido la responsabilidad del gobierno de la Nación" y el clima que se vivía, "perturbado por el encono y la maledicencia", presentó su renuncia al interventor rector de la Universidad Nacional de Córdoba (UNC), Lisardo Novillo Saravia. ${ }^{19}$

17. Según cuenta Félix Martín, Amadeo Sabattini les dijo que se queden en sus cargos pero no les dio mayores explicaciones. A la postre, fue incapaz de contenerlos. Entrevista de César Tcach con Félix Martín (4/4/1995). Cabe consignar que este destacado dirigente juvenil, de origen rosarino y educado en Bell Ville, fue subsecretario de Gobierno durante la última fase del gobierno de Santiago del Castillo. En 1958 se convirtió en ministro de Gobierno durante la administración frondicista de Arturo Zanichelli, en Córdoba.

18. Sobre la crisis ministerial de octubre, véase BUCHRUCKER, Cristián, Nacionalismo y Peronismo, Sudamericana, Buenos Aires, 1987, p. 281.

19. YADAROLA, Mauricio, Mi última lección en la Cátedra de la Universidad, mecanografiado, Córdoba, 29 de noviembre de 1943. 


\section{E1 Partido Demócrata: ¿una luz al final del túnel?}

El golpe de junio encontró al Partido Demócrata de Córdoba sumido en una profunda crisis interna. Las elecciones internas de abril, destinadas a elegir al nuevo comité central y a los representantes cordobeses en la Convención Nacional del partido, fueron acusadas de fraudulentas -y por ende, cuestionadas en su legitimidad- por los sectores renovadores encabezados por José Aguirre Cámara. De acuerdo con Octavio Capdevila, otro de sus referentes, se había querido "eliminar la gravitación del sector democrático del partido", con el "concurso entusiasta del presidente del Comité Nacional", Gilberto Suárez Lago, quien se desempeñaba asimismo, como interventor en el distrito Córdoba. ${ }^{20}$

En mayo, la convención provincial del Partido Demócrata otorgó un nuevo golpe a los sectores renovadores. Inaugurada por el presidente del PD, el senador nacional José Heriberto Martínez, contó con la asistencia de 340 convencionales quienes a su vez designaron - no por medio del voto sino del procedimiento de proclamación- a Pedro J. Frías como presidente de la convención. Esta resolvió eliminar la representación de las minorías en la elección primaria de candidatos a cargos electivos, pero también en el comité central, y organismos departamentales y de circuito. Pese a las protestas de Aguirre

20. Se acortaron los plazos de inscripción y depuración de los padrones, no se respetó el requisito de antigüedad para votar (art. 20 de la carta orgánica partidaria) y se formó -según lo denunciado- "una junta electoral de una parcialidad inaudita”. La Voz del Interior, Córdoba, 17/05/1943.
Cámara y otros convencionales, la decisión fue tomada y legitimada con un argumento tan sencillo como contundente, expresado por J. H. Martínez: "Las minorías en los partidos políticos llevan el germen de la disolución y a las divergencias interminables". ${ }^{21}$

Pero las resoluciones de la convención fueron más allá de los límites de Córdoba. La convención expresó su "solidaridad" y "adhesión" al presidente de la República, Dr. Ramón Castillo". ${ }^{22}$ Asimismo, ofreció un voto de aplauso para su ministro (e integrante del PD cordobés), Guillermo Rothe.

Las circunstancias descriptas permiten comprender las razones por las cuales, unas semanas después, el Partido Demócrata cordobés tenía dudas y dificultades para expresar su apoyo al nuevo gobierno. En rigor, se había derrocado a un presidente que ellos habían apoyado.

La voz discordante, fue la del sector renovador, el autodenominado "Núcleo Popular y Democrático". En un comunicado que firmaron los ex diputados nacionales José Aguirre Cámara, Benjamín Palacio y Clodomiro Carranza, y varios senadores provinciales, los acontecimientos fueron percibidos con esperanza. En una declaración pública justificó el levantamiento militar porque "el fraude sistemático había disuelto los partidos" y cerrado el camino de las urnas a las fuerzas opositoras. Más aún, "el Congreso no contaba", y "todas las válvulas estaban tapadas". Su postura era clara: las fuerzas políticas conservadoras "no pueden buscar su predominio en el falseamiento del sufragio".

21. Los Principios, Córdoba, 03/05/1943 y 17/05/1943.

22. Ibídem. 
Tampoco deben "abdicar de su autonomía, en aras de la voluntad presidencial”. Esta posición política descansaba en una interpretación filosófica progresista de lo que significaba el conservadorismo: "Las fuerzas políticas conservadoras no tiene por qué hacer suya en lo por venir la causa de los poderosos. Tampoco tendrán que olvidar que conservar es evolucionar. La inmovilidad no conserva. La regresión destruye". ${ }^{23} \mathrm{El}$ comunicado concluía expresando su confianza en el propósito manifiesto de los militares, a saber, defender las instituciones y restituir derechos y garantías.

\section{Expectativas cruzadas: la Iglesia Católica y los partidos de izquierda}

Tras el golpe, el diario del Arzobispado expresaba en su editorial, titulado "Fe y serenidad" su apoyo al golpe militar: "tengamos fe en las virtudes permanentes de la nacionalidad, tantas veces reflejadas en la acción heroica de las Fuerzas Armadas". ${ }^{24}$ La difundida identificación de la esencia de la nacionalidad con las virtudes y el carácter forjado en los cuarteles, constituía un lugar común de los valores promovidos desde el ámbito eclesiástico y servía como mecanismo de legitimación de la acción militar.

En las semanas siguientes, la prédica católica se orientó a un combate que intentaba corregir los dos aspectos menos gratos del gobierno radical saliente: su política educativa orientada hacia el laicismo escolar y las libertades y derechos que disfrutaba en Córdoba -a

23. La Voz del Interior, Córdoba, 20/06/1943.

24. Editorial de Los Principios, Córdoba, 05/06/1943.

42 diferencia del resto del país- el Partido Comunista.

En rigor, en su toma de partido en la controversia educacional, la Iglesia cordobesa tenía como enemigos no solo al laicismo que impedía la formación integral en base a valores católicos sino al normalismo que conducía a la formación de maestros fuera de su influencia y con marcos pedagógicos distantes de sus preferencias. En relación a esto, cabe recordar el papel clave que tuvieron durante el gobierno sabattinista de Santiago del Castillo (194043), los pedagogos Saúl Taborda (designado director del Instituto Pedagógico de la Escuela Normal Superior en 1942) y Antonio Sobral, nombrado presidente del Consejo de Educación en abril de 1943. El propio Santiago del Castillo estaba formado en el normalismo y tenía fuertes convicciones al respecto. ${ }^{25}$

Cabe añadir que la urgencia católica sobre el tema estuvo motivada, además, por una medida aprobada por el gobernador radical poco antes de su renuncia: la aprobación del Estatuto del Magisterio que preveía concursos docentes y un régimen de estabilidad laboral. En su artículo 40, se explicitaba: "En ningún caso, las ideas políticas, religiosas o filosóficas de los maestros podrán ser causal de sanciones disciplinarias de ninguna índole, siempre que no hagan propaganda de ellas dentro de la escuela” ${ }^{26}$ La medida, que afectaba las prácticas de los colegios privados religiosos -suponía un veto a la propaganda religiosa- debía empezar a regir en enero de $1944 .{ }^{27}$ Tampoco eran de

25. Véase, DIAZ, Sergio Raúl, "1940/1943: un maestro en el poder", en Aproximaciones al gobernador Del Castillo, Gobierno de la Provincia de Córdoba, 1998, pp. 59-66.

26. La Voz del Interior, Córdoba, 19/06/1943.

27. E1 Estatuto del Magisterio fue redactado por el 
su agrado, instituciones culturales cordobesas de claro tinte laicista y anticlerical, como el Colegio Libre de Cultura Popular, dirigido por Juan Zanetti. ${ }^{28}$

Una segunda línea de preocupaciones, vinculada a la anterior, centraba su interés en la lucha contra el Partido Comunista.Poco tiempo antes, el 1 de mayo de 1943, una multitudinaria manifestación obrera en la que predominaban comunistas y socialistas, había recorrido las calles de la ciudad, siendo encabezada por la banda de música del Escuadrón de Seguridad de la policía provincial. Esta vigencia plena de las libertades públicas era reconocida en el acto por el socialista José Michelón -referente de la Confederación General del Trabajo (CGT) que lideraba a nivel nacional Pérez Leiros- : en Córdoba, sostuvo, "se respira un clima de libertad". Asimismo, el dirigente comunista y de la Federación Universitaria de Córdoba (FUC), Fernando Nadra, contrapuso ese clima que se vivía en Córdoba, "ciudad cuna de la Constitución”, con el Estado de Sitio que emanado de las autoridades nacionales tenía vigencia desde hacía más de un año. ${ }^{29}$

presidente del Consejo de Educación, Antonio Sobral. Fue aprobado por ese organismo y luego por el propio gobernador. Un editorial del matutino católico, posterior al golpe militar, señalaba con crudeza que el Consejo de Educación estaba en manos de "elementos de izquierda". Los Principios, Córdoba, 28/06/1943. Unos días antes, otro editorial había definido su norte "en los ideales superiores de Dios, Patria y Hogar". Editorial de Los Principios, Córdoba, 24/06/1943.

28. El Colegio Libre de Cultura Popular funcionaba en la Escuela Vicente de Olmos, situada frente a la plaza Vélez Sarsfield. Fue intervenido por el gobierno en 1944.

29. La Voz del Interior, Córdoba, 11/3/1943. La marcha se extendió desde la plaza General Paz hasta la plaza Vélez Sarsfield y contó también con la participación de oradores de la UCR. El diputado nacional Reginaldo Manubens Calvet acuso al gobierno nacional de ser "hijo del fraude" y amordazar a la prensa. Ibidem.
Tras el golpe, el diario del Arzobispado tenía claro el sesgo anticomunista de las nuevas autoridades militares. Por ello, un editorial de Los Principios, denominado "La Prédica Comunista”, expresaba su asombro por un panfleto ampliamente difundido, en la que el PC expresaba su actitud comprensiva del levantamiento militar. ¿Cómo pueden sostener esa posición, si el gobierno nacional les clausuró sus locales?, se preguntaba el editorialista. Al respecto recordaba que también en Córdoba se había dispuesto análoga medida. ${ }^{30}$

En rigor, la posición del PC fue variando en sus matices y expectativas, como la de gran parte del resto del arco político. Tras el golpe, el diario de ese partido, La Hora, sólo pudo publicar dos números: el segundo día posterior al golpe, su local fue saqueado y clausurado por la policíaca Sección Especial contra el comunismo y detenidos sus principales redactores. En esas circunstancias, el PC denunció al gobierno -al que calificó de reaccionario- y llamó a formación de un gobierno de unidad de los partidos democráticos. Pero el 7 de junio, la asunción del general Ramírez abrió nuevas expectativas, en virtud de sus promesas de tono democrático y republicano. En ese marco se inscribía el panfleto comunista, que por otra parte, estaba en correspondencia con las inclinaciones aliadófilas del nuevo presidente. En análoga sintonía, ese mismo día, el Comité Ejecutivo Nacional del Partido Socialista expresó en una declaración que era indispensable que "las organizaciones políticas, civiles y democráticas sean oídas acerca de los procedimientos" para lograr la recuperación de la democracia, la normalización constitucional y la nueva orientación de la política

30. Los Principios, Córdoba, 19/6/1943. 
internacional a seguir. ${ }^{31}$ Aún en septiembre de 1943, el Partido Socialista seguía siendo cauto. En un memorándum elevado al presidente Ramírez denunciaba la influencia de sectores nacionalistas en el gobierno, esperaba de su gestión una mayor cuota de libertades públicas y expresaba su preocupación por el aislamiento internacional argentino. ${ }^{32}$

Pero el curso de los acontecimientos, no acompañó las expectativas de socialistas y comunistas. Como reconoce la historia oficial del PC: "Las promesas de Ramirez no pasaron de ser tales, pues bajo la presión del sector más acentuadamente fascista del GOU fue realizando los objetivos que éstos últimos se habían propuesto realizar al dar el golpe de Estado; y, cuando quiso resistir esa presión -como sucedió en enero de 1944 al romper relaciones con las potencias del Ejefue desplazado violentamente del poder por la combinación Farrell-Perón”. ${ }^{33}$

31. Córdoba, Córdoba, 7/6/1943.

32. CAMARERO, Hernán y HERRERA, Carlos Miguel, El Partido Socialista en Argentina, Prometeo, Buenos Aires, 2005, p. 348.

33. PARTIDO COMUNISTA ARGENTINO. COMITÉ CENTRAL, Esbozo de Historia del Partido Comunista de la Argentina, Anteo, Buenos Aires, 1947, pp. 108-109. Cabe recordar que el diario La Hora había sido dirigido desde 1940 por Benito Marianetti, Emilio Troise y Orestes Ghioldi. Tras su clausura en 1943, reapareció en 1945 hasta 1950 cuando fue nuevamente prohibido. Reapareció brevemente entre mayo de 1958 y enero de 1959, siendo su secretario de redacción Ernesto Giudici. Véase, PETRA, Adriana, "Intelectuales y política en el comunismo argentino: estructuras de participación y demandas partidarias", en Anuario IEHS, Tandil, 2012, No 27 , pp. 27-56.

\section{A modo de epílogo}

Tulio Halperin Donghi señaló que el golpe de junio "puso fin a la agonía de la República imposible”, y que, en contraste con el levantamiento militar de 1930 no fue el desenlace de la agitación promovida por sectores civiles y políticos sino que fue protagonizado por la corporación armada en pleno. Destacó, asimismo, que en ningún caso, las proclamas revolucionarias pretendieron ser fundacionales, sino más bien un correctivo de la degeneración del orden institucional. ${ }^{34}$ Ambas observaciones se combinan para explicar lo ocurrido inmediatamente después: el amplio eco que el golpe encontró durante los días siguientes en los sectores civiles. $\mathrm{Al}$ no aparecer como faccioso (dado que no se podía identificar con la acción de ningún sector civil) ni como anticonstitucional dado que su pretensión confesa era reparadora de un orden democrático y republicano más genuino, cosechó apoyos cruzados de distintos sectores.

En el caso del radicalismo de Córdoba, el apoyo se tradujo en la cesión de su gobierno, electo en comicios limpios y democráticos, y en la aceptación de un cargo de relevancia por parte de su ex gobernador, Santiago del Castillo. Pero una buena dosis de ambigüedad e incertezas acompañó sus decisiones desde los primeros momentos. Como hemos visto, la postura de Amadeo Sabattini fue posibilista, "no aventuremos opiniones" y "tengamos cuidado", señaló el 19 de junio de $1943 .{ }^{35}$ En

34. HALPERIN DONGHI, Tulio, La República imposible (1930-1945), Ariel, Buenos. Aires, 2004, pp. 268 y 291.

35. La Voz del Interior, Córdoba, 20/6/1943. 
su mirada, la proa regeneradora en que las autoridades militares decían inspirar su acción, constituía un camino posible pero no seguro. El comité central partidario, por su parte, hizo explícito desde un principio la contraposición entre las palabras del gobierno militar y su correlato en los hechos, al denunciar la "evidente contradicción" de un gobierno que decía defender la democracia y la constitución y liquidaba, al mismo tiempo su expresión más consecuente en el orden provincial: el gobierno de Córdoba liderado por Santiago del Castillo y Arturo Illia.

Es probable que un núcleo de ideas más profundo latiese en la tolerancia inicial del sabattinismo hacia los oficiales que protagonizaron el golpe: la convicción de la necesidad de evitar un divorcio entre la UCR y las Fuerzas Armadas. En diversas ocasiones sostuvo que uno de los errores más grandes del radicalismo fue dejarse divorciar del Ejército por las fuerzas de la oligarquía. En otras palabras, no había que regalarle los militares a los sectores conservadores. Este diagnóstico estuvo en la base de la ilusión, tan prematura como efímera, de nueva luna de miel entre la institución militar y el partido que se consideraba abanderado de las libertades ciudadanas.

Una segunda convicción acompañaba este razonamiento, a saber, los militares terminarían necesitando del partido más popular de la Argentina. Aún en noviembre de 1943, Amadeo Sabattini expresaba: "Estos militares necesitan de la UCR por ser la única salvación del país". Empero, en ese mismo mes también reconocería -en una carta personal a su amigo y correligionario Guillermo Stuckerlas dificultades de su empresa: "Que esto sea una dictadura militar fascista regenteada por los jesuitas, eso no lo duda nadie ni lo he dudado de la primera hora". ${ }^{36}$ Ciertamente, el anticlericalismo del máximo líder del radicalismo de Córdoba debió haber tendido un manto de duda sobre las motivaciones de los militares golpistas. Pero su condescendencia inicial fue el detonante de serias disidencias en el interior de su propio sector político partidario, sobre todo, en los sectores juveniles identificados con las banderas del antifascismo en la segunda guerra mundial.

El golpe de junio encontró en una situación incómoda al Partido Demócrata. El mes anterior, su convención provincial había expresado su adhesión al gobierno nacional y rubricado con un voto de aplauso a su ministro de Justicia e Instrucción Pública, Guillermo Rothe. Por ello, solo el sector minoritario -conocido como Núcleo Popular y Democrático- encabezado por José Aguirre Cámara expresó de modo franco sus expectativas en el poder de normalización institucional que podían tener los militares.

E1 Partido Comunista, por su parte, compartió con el radicalismo cierta ambigüedad inicial. Tras el trauma generado por el saqueo de su periódico nacional, $L a$ Hora, se ilusionó con el desplazamiento del general Rawson por el general Ramírez y seguramente en su ambivalencia pesó la posibilidad de contar con un gobierno que se ubicase del lado de los aliados y la Unión de Repúblicas Socialistas Soviéticas (URSS) en la segunda guerra mundial. Su ocaso en el verano de 1944 puso punto final a sus expectativas. En las antípodas de éstas, pasó a ser víctima predilecta de la represión política.

El socialismo cordobés corrió un tránsito

36. TCACH, César, Sabattinismo y Peronismo, Biblos, segunda edición, Buenos Aires, 2006, pp. 64-65. 
análogo. En este punto conviene aclarar que ya a mediados de 1943, la definición del enemigo comunista era por demás amplia. Un caso ilustrativo al respecto fue el de la agrupación antifascista Acción Argentina, cuya junta ejecutiva había expresado su apoyo al golpe militar por interpretar que abría las puertas a un nuevo ciclo democrático en el país. Pese a su perfil antifascista y antistalinista, en julio de 1943 todos sus locales fueron clausurados por considerarse que sus actividades favorecían al comunismo. Es que la resolución militar que censuraba las actividades comunistas, incluía a "toda asociación que no obstante tener propósitos públicamente proclamados, ajenos a la difusión de esa ideología, en el hecho se hayan constituido en vehículo para el desarrollo de la misma". ${ }^{37}$ Es por ello que las expectativas iniciales de los partidos de izquierda fueron pronto defraudadas. Así, en la provincia de Córdoba, la CGT reunificada en 1944 bajo la dirección del ferroviario socialista Bruno Herrera se convirtió -como acertadamente precisó Torcuato Di Tella- en "un foco de resistencia" contra el gobierno nacional. $^{38}$

Quizá, el sector organizado que vio con mayor certeza el rumbo de los acontecimientos fue la Iglesia Católica. Desde un principio, era claro para ella que había llegado la hora de arrinconar al laicismo escolar, imponer la enseñanza religiosa obligatoria y liquidar cualquier vestigio de marxismo en la sociedad argentina. Para el caso de Córdoba, suponía también poner punto final a esa suerte de promiscuidad que percibían en las relaciones

37. BISSO, Andrés, Acción Argentina, Prometeo, Buenos Aires, 2005, pp. 235-236.

38. DI TELLA, Torcuato, Perón y los sindicatos, Buenos Aires, Ariel, 2003, p. 131. entre radicales e izquierdistas; como la evidenciada en la manifestación -ya descriptadel $1^{\circ}$ de mayo de ese año, y poco antes, en el gran acto organizado por el Centro de Empleados de Comercio en el estadio Córdoba Sport Club a favor de un sistema jubilatorio y su extensión a las mujeres con 25 años de trabajo. En esa oportunidad habían compartido la tribuna el socialista Angel Borlenghi con el gobernador Santiago del Castillo y el intendente de la ciudad Donatto Latella Frías. ${ }^{39}$

La identificación de las Fuerzas Armadas con los valores permanentes de la nacionalidad, le proveía al clericalismo cordobés una guía para la acción que dotaba de coherencia a sus posicionamientos políticos. La fuerza de estos derivaba también de la legitimidad otorgada por el consentimiento vaticano. Ya en 1940, en la descripción que hacía la Revista Militar de la audiencia concedida por el papa Pío XII a una misión militar argentina, se destacaba que el pontífice les recalcó su objetivo de hacer impenetrables las fronteras del país, al "moderno alejamiento de Dios". ${ }^{40}$ Para el clericalismo cordobés había llegado por fin la hora de poner punto final a la experiencia sabattinista, que se había iniciado siete años antes con el rechazo del gobernador electo a jurar por Dios al asumir la primera magistratura de la provincia.

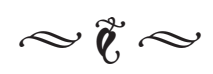

39. La Voz del Interior, Córdoba, 11/3/1943.

40. ZANATTA, Loris, Estado Liberal..., Op., Cit., p. 364. 
Recibido: 10-06-2015

Aceptado: 24-09-2015

Publicado: 21-12-2015 


\section{Bibliografía}

ACHAVAL BECU, Inés y GONZALEZ ACHAVAL, María, "Repercusiones del golpe de 1943 en Córdoba. Actores y culturas políticas", ponencia presentada en VI Jornadas de Historia de Córdoba, Junta Provincial de Historia de Córdoba, 2006.

BISSO, Andrés, Acción Argentina, Prometeo, Buenos Aires, 2005.

BUCHRUCKER, Cristián, Nacionalismo y Peronismo, Sudamericana, Buenos Aires, 1987.

CAMARERO, Hernán y HERRERA, Carlos Miguel, El Partido Socialista en Argentina, Prometeo, Buenos Aires, 2005.

DEVOTO, Fernando, "Para una reflexión del golpe del 4 de junio de 1943”, en Estudios Sociales, Santa Fe, 2014, No 46, pp. 171-186.

DIAZ, Sergio Raúl, “1940/1943: un maestro en el poder”, en Aproximaciones al gobernador Del Castillo, Gobierno de la Provincia de Córdoba, 1998.

DI TELLA, Torcuato, Perón y los sindicatos, Buenos Aires, Ariel, 2003.

HALPERIN DONGHI, Tulio, La República imposible (1930-1945), Ariel, Buenos. Aires, 2004.

JUNTA PROVINCIAL DE HISTORIA DE CÓRDOBA, Córdoba entre campanas y chimeneas, Junta Provincial de Historia de Córdoba, 2007.

MACOR, Darío e IGLESIAS, Eduardo, El peronismo antes del peronismo, Universidad Nacional del Litoral, Santa Fe, 1997.

PARTIDO COMUNISTA ARGENTINO. COMITÉ CENTRAL, Esbozo de Historia del Partido Comunista de la Argentina, Anteo, Buenos Aires, 1947.

PETRA, Adriana, "Intelectuales y política en el comunismo argentino: estructuras de participación y demandas partidarias", en Anuario IEHS, Tandil, 2012, No 27, pp. 27-56.

POTASH, Robert, El Ejército y la Politica en Argentina, T. I, Hyspamerica, Buenos Aires, 1985.

SIDICARO, Ricardo, La politica mirada desde arriba, Sudamericana, Buenos Aires, 1993.

TCACH, César, Sabattinismo y Peronismo, Sudamericana, Buenos Aires, 1991.

TCACH, César, Sabattinismo y Peronismo, Biblos, segunda edición, Buenos Aires, 2006.

YADAROLA, Mauricio, Mi última lección en la Cátedra de la Universidad, mecanografiado, Córdoba, 29 de noviembre de 1943.

ZANATTA, Loris, Del Estado Liberal a la Nación Católica, Universidad Nacional de Quilmes, Buenos Aires, 1996. 